NASA Technical Memorandum 102073

\title{
Space Station Freedom Photovoltaic Power Module Design Status
}

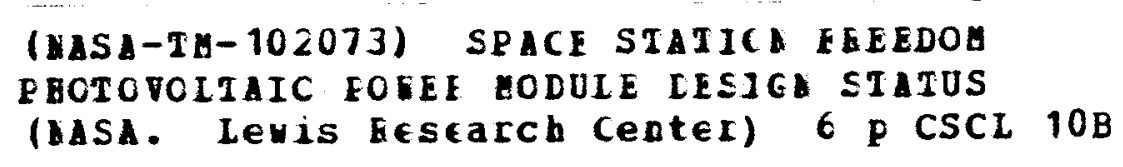

\begin{abstract}
Amador P. Jimenez
Rockwell International

Rocketdyne Division

Canoga Park, California
\end{abstract}

and

Mark A. Hoberecht

Lewis Research Center

Cleveland, Ohio

\section{Prepared for the}

24th Intersociety Energy Conversion Engineering Conference cosponsored by the IEEE, AIAA, ANS, ASME, SAE, ACS, and AIChE Washington, D.C., August 6-11, 1989 
SPACE STATION FREEDOM PHOTOVOLTAIC POWER MOOULE DESIGN STATUS

\author{
Amador $P$. Jimenez \\ Rockwell International \\ Rocketdyne Division \\ 6633 Canoga Avenue \\ Canoga Park, California 91303 \\ and \\ Mark A. Hoberecht \\ National Aeronautics and Space Administration \\ Lewis Research Center \\ Cleveland, Ohio 44135
}

\section{ABSTRACT}

Electric power generation for space station Freedom will be provided by four photovoltaic (PV) power modules using silicon solar cells during Phase I operation. Each PV power module requires two solar arrays with 32800 solar cells generating $18.75 \mathrm{~kW}$ of dc power for a total of $75 \mathrm{~kW}$. A portion of this power will be stored in nickelhydrogen batteries for use during eclipse, and the balance will be processed and converted to $20 \mathrm{kHz}$ ac power for distribution to end users through the power management and distribution system. The design incorporates an optimized thermal control system, pointing and tracking provision with the application of gimbals, and the use of orbital replacement units (ORU's) to achieve modularization.

Design status of the PV power module, as derived from major trade studies, is discussed at hardware levels ranging from component to system. Details of the design are presented where appropriate.
\end{abstract}

\section{INTRODUCTION}

Rockwell International, through its subsidiary, Rocketdyne Division, is under contract to the National Aeronautics and Space Administration/Lewis Research Center (NASA Lewis) to design and build as Work Package 4 the electric power system (EPS) for the SSF. Work associated with development and production of the PV power modules is a significant portion of this activity. This paper presents an updated design status of the PV power module as derived from major trade studies, with discussion of hardware levels ranging from component to system [1].

\section{PV POWER MODULE HARDWARE DESCRIPTION}

The PV power module is shown in Fig. I. In both its launch packaged and final on-orbit configuration, the PV power module is composed of three combined assemblies made up of several individual assemblies and/or subsystems. These combined assemblies are the integrated equipment assembly (IEA) and two solar array/beta gimbal combined assemblies, which are discussed in the following sections.

\section{Integrated Equipment Assembly}

Each IEA is located within the truss bay adjacent to the bay that contains the two solar arrayl beta gimbal combined assemblies. The IEA provides the structural framework in the form of a flat plate for integrating ORU's and other hardware from various individual subsystems.

The first of these subsystems is the thermal control subsystem (TCS). The primary function of the TCS is to maintain a safe operating temperature for all IEA ORU's by removing waste heat and rejecting it to space. The ICS is composed of heat-acquisition hardware (utility plates), conduits for thermal transport, and a heat-rejection device (radiator). Ammonia is the working fluid for the subsystem, and mechanical pump ORU's are used to move the fluid through the conduits to the radiator. The utility plates essentially form the shell of the IEA structural framework to which all the ORU's are mounted. In addition to the two TCS pump ORU's, utility plates support ORU's from the energy storage subsystem (ESS) and electrical equipment subsystem (EES).

The PV power module ESS consists of five nickel-hydrogen batteries and five battery charge/ discharge unit ORU's. Each battery consists of three battery assembly ORU's with 30 seriesconnected individual pressure vessel nickelhydrogen cells of 81-Ah capacity for a total of 90 cells per battery. The ESS for each PV power module is thus composed of 20 total ORU's. Each battery and its respective charge/discharge unit are mounted to an individual utility plate on the IEA. The ESS accepts nearly 50 percent of the power generated by the solar arrays during the sunlight portion of the orbit to charge the nickel-hydrogen cells. These cells are then discharged during the eclipse portion of the orbit in order to provide power for SSF.

The EES for the PV power module is composed of hardware from both the $d c$ and ac portions of the Power Management and Distribution (PMAD) system. This hardware consists of ORU's that control, condition, and convert the solar array and battery source power supplied to the PMAD system. These include two photovoltaic controllers, two dc switching units for interconnection of array and 
battery source power, two main inverter units that convert de to ac power, two main bus switching units, and two power distribution and control units for a total of 10 ORU's per PV power module EES, all mounted to utility plates on the IEA. A power flow diagram for the PV power module is shown in Fig. 2. The responsibility of controlling, conditioning, and delivering the right amount of power to the end users, including peaking and contingency, ultimately rests with the PMAD system.

\section{Solar Array/Beta Gimbal Combined Assemblies}

The solar array assembly consists of 32800 solar cells per PV power module for a SSF total of 262400 cells that will be wired together in series-parallel groups to deliver $160 \mathrm{~V}$ dc power. This power output from the solar array flows through a sequential shunt unit ORU to the IEA. An extendable and retractable mast supports the solar array assembiy. The mast is attached to a singleaxis beta gimbal assembly, which in conjunction with the alpha gimbal assembly, maintains a sunpointing orientation of the solar array for maximum capture of sunlight. The beta gimbal assembly provides seasonal pointing adjustment of the array-tosun plane.

\section{DESIGN CONSIDERATIONS}

The design of the PV power module has been influenced by a number of considerations that have determined, to varying degrees, both its physical and functional characteristics. Some of these have been dictated by specific SSF overall design requirements, and are therefore constrained. Many other characteristics are flexible, and are impacted by these considerations: mass and volume, reliability and maintainability, PV power module integration, and cargo element launch packaging considerations.

\section{Mass and Volume}

It is not difficult to understand how the design of any spacecraft is impacted by its mass and volume requirements, which play a major role in the economics of any space program. This is more evident with the SSF because of its sheer size, which is the largest structure ever to be assembled in space by more than an order of magnitude. It will be ferried into space using numerous Shuttle Orbiter flights. Obviously, the cost of launching a structure this size will be prodigious, and this situation has placed mass and volume in the forefront of design drivers.

\section{Reliability and Maintainability}

When constructed and deployed in its circular low-Earth-orbit, the SSF will be 180 miles from Earth. For servicing and resupply, several logistics flights per year will be scheduled for the Shuttle Orbiter. It becomes apparent with this frequency of logistics that the SSF and its ORU's should be highly reliable. Rocketdyne has the responsibility to deliver a reliable and dependable product, and has taken the necessary steps to ensure that all PV power module hardware and software comply with program reliability requirements.

Maintainability is crucial to the successful long-term operation of a spacecraft, with low maintenance costs being another critical design driver. The design of the PV power module is tailored to reduce the cost of on-orbit maintenance by packaging similar functional hardware in ORU's that can be installed or removed by robotic or extravehicular activity (EVA) methods. Assemblies and subsystems are designed so that removal or replacement of ORU's will not entail disturbance of other assemblies and/or subsystems. The main truss, which provides structural support for the entire Space Station Freedom, allows a corridor to facilitate ORU access.

\section{PV Power Module Integration}

Integration of the PV power module, both internaliy with its assemblies and subsystems, and externaliy into the EPS, poses numerous unique challenges. The IEA is an example of internal PV power module integration. In order to successfully integrate the TCS, ESS, and EES, a configuration that combines them in a compact and systematic way had to be evolved. This iterative effort led to the adoption of the concept of a flat-plate IEA as a structural framework whose faces could accommodate plates to support the ORU boxes which house the various subsystem hardware. These utility plates provide the thermal, electrical, and structural interfaces for the IEA ORU's. An example of external PV power module integration is design commonality of beta gimbals with the solar dynamic (SD) power module, which will be in use during Phase II operation of Freedom. Both the PV and SD beta gimbals have similar design requirements. By using one common design for both applications, costs can be minimized.

\section{Cargo Element Launch Packaging}

At least 20 flights of the Shuttle Orbiter will be required to carry freedom into space. Since its payload bay can hold only a limited amount of cargo, it is imperative that imaginative launch packaging techniques be exercised to maximize the use of available payload bay space in order to minimize the number of required flights. In addition, the assembly sequence should be planned carefully so that elements in the order they are needed and prioritized are ferried into space to maintain a smooth transition as Freedom is constructed and functional capabilities are expanded. Power is required beginning with the first launch, dictating that a PV power module cargo element be manifested on the first assembly flight. The other hardware manifested on this flight will, to some extent, also drive the design of the PV power module.

\section{TRADE STUDIES}

Two major trade studies have recently been performed on the PV power module. The first involved the selection of the thermal control subsystem, while the second dealt with the configuration 
for the IEA. Both trade studies used the baseline PV power module as derived from Freedom Phase B effort as the starting point. As the Phase C/D contractual effort has proceeded, design activities have identified these two areas as those requiring major trade studies in order to arrive at designs which would best satisfy Space Station Freedom program requirements. Evaluation and final acceptance of these results allows further PV power module design activities to continue and key Freedom program milestones to be met.

\section{Thermal Control Subsystem}

An extensive trade study was conducted at Rocketdyne in order to compare three different thermal control subsystems for the PV power module: two-phase/heat pipe radiator, single-phase/ heat pipe radiator, and single-phase/direct radiator. These subsystems are shown in fig. 3 . It should be noted that each subsystem has its own inherent advantage for certain applications. Generally, two-phase subsystems require a lower flow rate for the same capacity with less pumping power, have nearly constant fluid supply temperatures, and are insensitive to changes in the heat load. However, the hardware associated with two-phase subsystems is usually of greater mass, its reliability is lower because of its complexity, and the development risk is higher due to limited performance data in a micro-g environment.

The study involved a series of analyses to determine the merits of each subsystem for the PV power module application based on a number of criteria, as shown in Table I. A positive ( + ) evaluation mark indicates the option has definite advantages in that particular area, a minus (-) denotes disadvantages, and a zero (0) shows no clear advantage or disadvantage over the other options. Typical parameters such as mass, volume, reliability, maintainability, and cost were included in the criteria list. The first two of these parameters favored the single-phase/direct radiator subsystem, while the latter three criteria were relatively equal for all the subsystems. Both flexibility and flow power favored the two-phase subsystem, but commonality was relatively equal for the three subsystems. Two of the remaining criteria, development risk and technology readiness, showed a decided advantage for the single-phase subsystems, especially that with the direct radiator. Launch packaging, the last criteria, was superior for the single-phase/direct radiator thermal control subsystem. Based on the overall results, the trade study indicates that the singlephase/direct radiator is clearly the favored subsystem and has been recommended for implementation into the PV power module.

\section{IEA Configuration}

A comprehensive trade study considering a large number of options was performed by Rocketdyne in order to determine the best configuration for the IEA. From an initial field of nine possible options, six were dropped on the basis of not meeting all the requirements defined in the applicable
NASA specifications. These requirements were used as the criteria for choosing the configuration that best satisfies, both physically and functionally, the requirements for the IEA. The three remaining options, shown in Fig. 4, were then analyzed and compared. They are the low profile IEA, the flat plate IEA as part of a fully deployable PV power module, and the flat plate IEA with integral launch cradle.

The list of criteria and the corresponding evaluation marks for the three options are listed in Table II. Once again, a positive $(+)$ mark indicates the option has definite advantages in that particular area, a minus (-) denotes disadvantages, and a zero (0) shows no clear advantage or disadvantage over the other options. The criteria included mass, assembly, maintainability, safety, technology readiness, and launch packaging. Cost as a direct function of mass and complexity was combined with mass because there is no marked difference in the design complexity of the three options. Mass calculations were made in connection with limited structural analyses for sizing the various members of the assembly.

The matrix indicates that the flat plate IEA with integral launch cradle has the least mass, hence cost. Combining launch cradle structure with IEA structure results in overall PV power module mass savings. This option also has the most favorable maintainability features because it is more easily accessed than the others. There is more clearance for ORU replacement, and additional locations for possible foot restraints than any of the other options. The sole benefit of the flat plate IEA as part of a fully deployable PV power module is its ease of assembly on-orbit, but this is at the expense of the other criteria. The low profile IEA had no positive evaluation marks. The combined results show that the flat plate IEA with integral launch cradle is the most effective configuration and, therefore, has been adopted by Work Package 4 as the baseline IEA configuration for the PV power module.

\section{SUMMARY}

Hardware designs for the PV power module have continued to evolve during Rocketdyne's Phase C/D contractual effort. These designs have in many cases been dictated by specific program requirements. In other cases however, major trade studies have been performed in order to select concepts that not only meet program requirements, but provide definite advantages over other less effective concepts. The design of the PV power module will continue to proceed, allowing key Freedom program milestones to be met.

\section{REFERENCE}

1. Vogt, S.T.; and Proetsche1, R.A.: Space Station Photovoltaic Power Module Design. Proceedings of the 23rd Intersociety Energy Conversion Engineering Conference, Vol. 3 , ASME, 1988, pp. 567-572. 
TABLE I. - THERMAL CONTROL SUBSYSTEM STUDY EVALUATION CHART

\begin{tabular}{|c|c|c|c|}
\hline Criteria & $\begin{array}{l}\text { Two-phase/ } \\
\text { heat pipe } \\
\text { radiator }\end{array}$ & $\begin{array}{c}\text { Single-phase/ } \\
\text { heat pipe } \\
\text { radiator }\end{array}$ & $\begin{array}{l}\text { Single-phase } \\
\text { direct } \\
\text { radiator }\end{array}$ \\
\hline $\begin{array}{l}\text { Mass } \\
\text { Volume } \\
\text { Reliability } \\
\text { Maintainability } \\
\text { Cost } \\
\text { Flexibillty } \\
\text { Flow power } \\
\text { Commonality } \\
\text { Development risk } \\
\text { Technology readiness } \\
\text { Launch packaging }\end{array}$ & $\begin{array}{l}+ \\
+ \\
+ \\
0 \\
- \\
- \\
-\end{array}$ & $\begin{array}{l}0 \\
1\end{array}$ & $\begin{array}{l}\downarrow \\
+ \\
+ \\
+\end{array}$ \\
\hline
\end{tabular}

TABLE II. - IEA CONFIGURATION STUDY EVALUATION CHART

\begin{tabular}{|l|c|c|c|}
\hline \multicolumn{1}{|c|}{ Criteria } & $\begin{array}{c}\text { Low profile } \\
\text { IEA }\end{array}$ & $\begin{array}{c}\text { Flat plate IEA, } \\
\text { fully deployable } \\
\text { PV power module }\end{array}$ & $\begin{array}{c}\text { Flat plate IEA, } \\
\text { integral } \\
\text { launch cradle }\end{array}$ \\
\hline Mass & - & 0 & + \\
Assembly & 0 & + & 0 \\
Maintainability & - & 0 & + \\
Safety & 0 & - & 0 \\
Technology readiness & 0 & 0 & 0 \\
Launch packaging & 0 & 0 & 0 \\
\hline
\end{tabular}

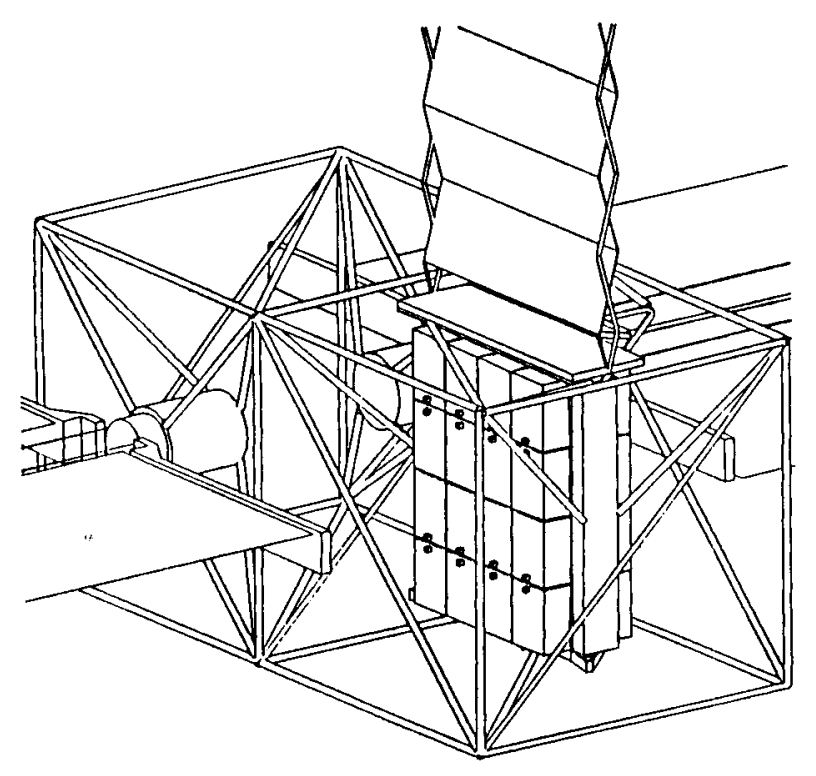

FIGURE 1. - PV POWER MODULE.

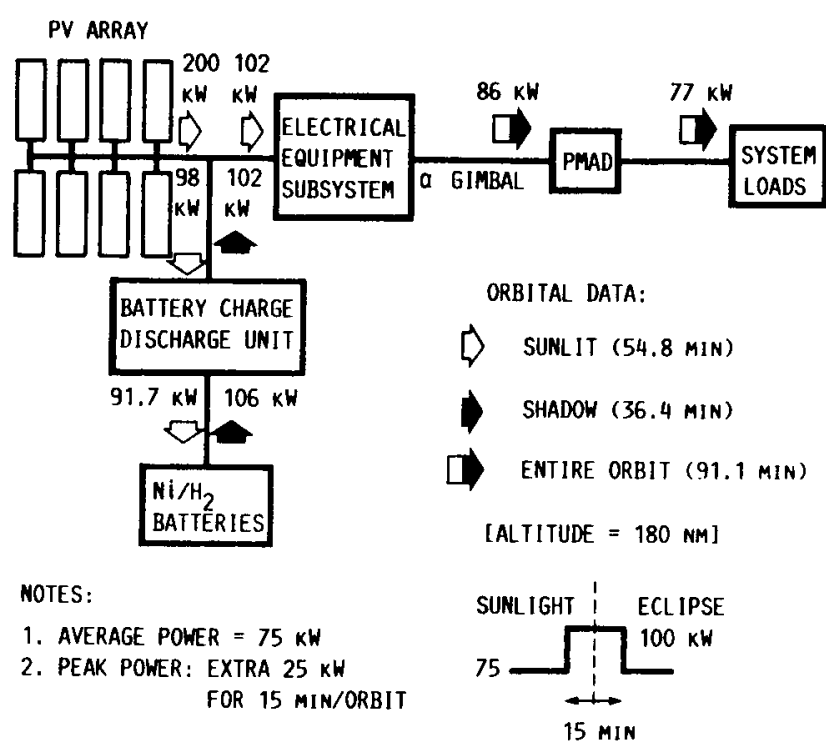

FIGURE 2. - POWER FLOW DIAGRAM. 


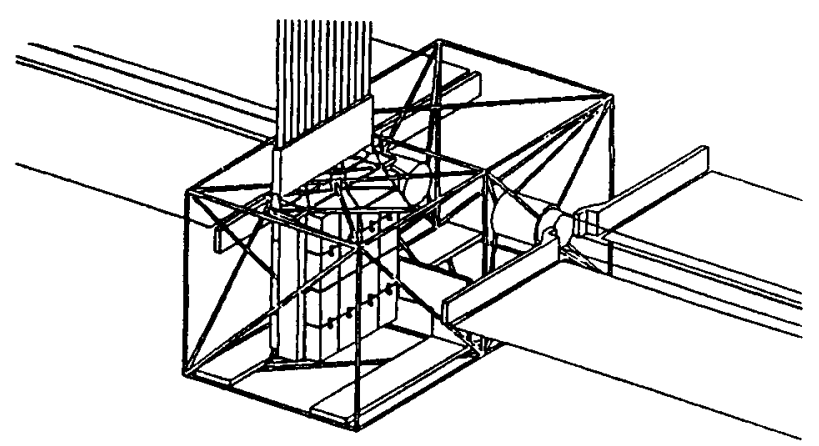

TWO-PHASE/HEAT PIPE RADIATOR

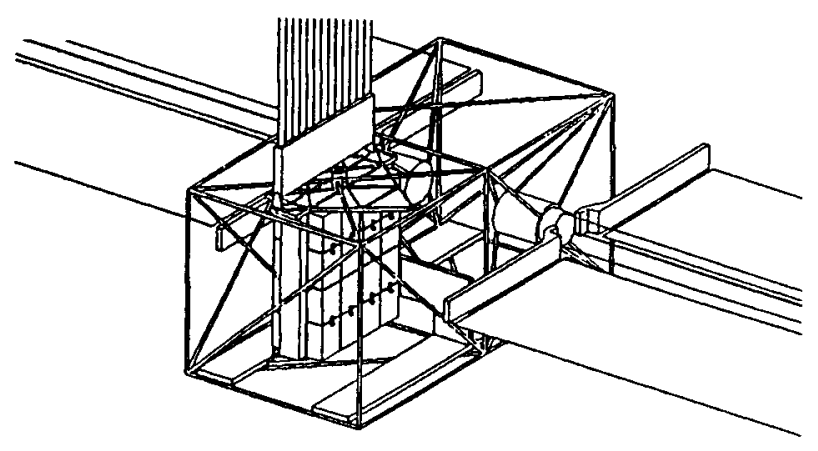

SINGLE-PHASE/HEAT PIPE RADIATOR

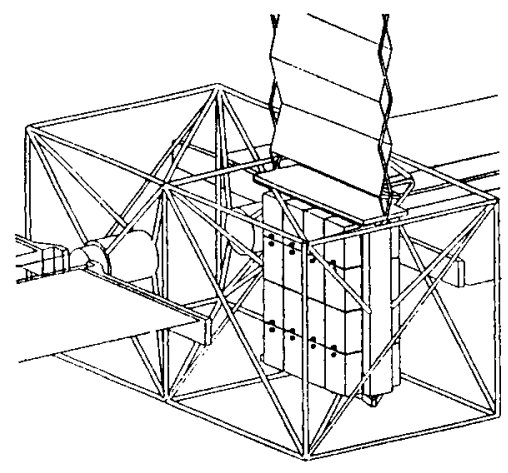

SINGLE-PHASE/DIRECT RADIATOR

FIGURE 3. - THERMAL CONTROL SUBSYSTEM OPTIONS.

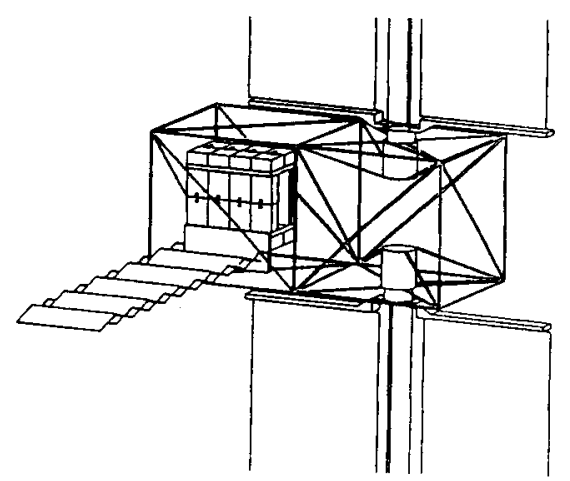

LOW PROFILE IEA

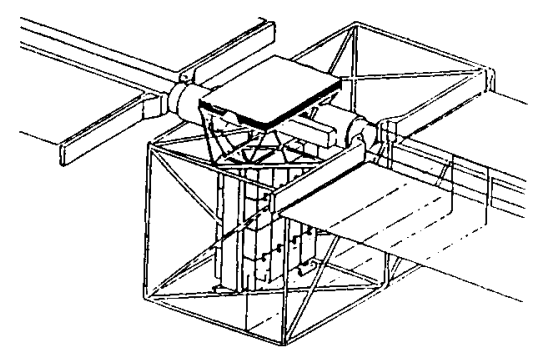

FLAT PLATE IEA, FULLY DEPLOYABLE PV POWER MODULE

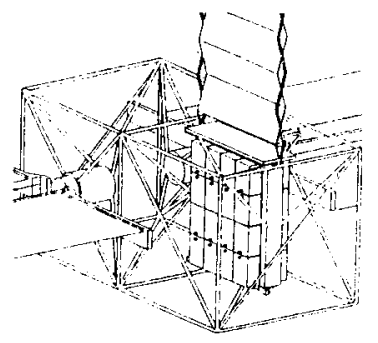

FLAT PLATE IEA, INTEGRAL LAUNCH CRADLE FIGURE 4. - IEA CONFIGURATION OPTIONS. 


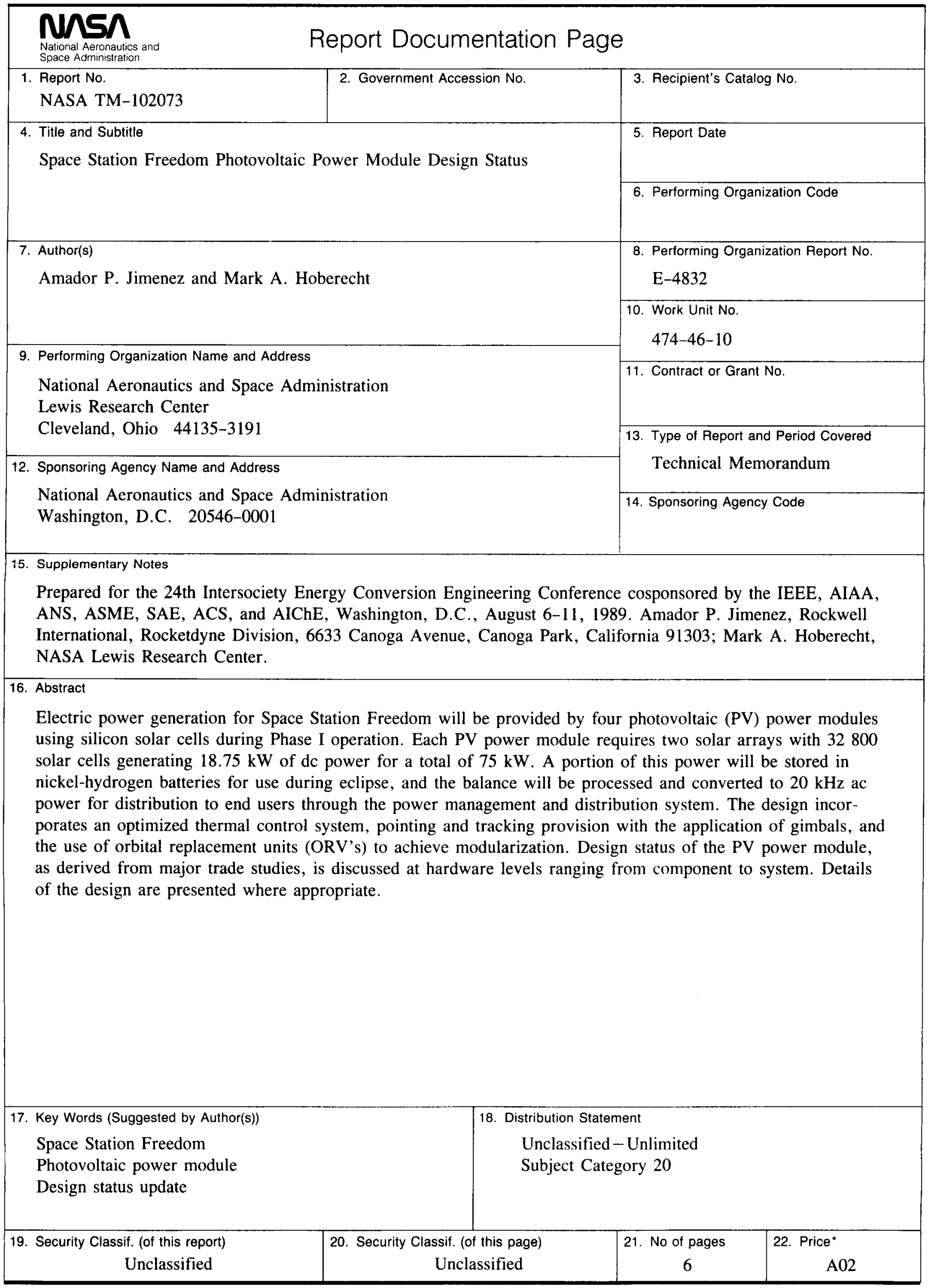

